\title{
Efficacy of Anti-Tumor Necrosis Factor- $\alpha$ Therapy Against Intestinal Behçet's Disease Complicated by Recurrent Enterocutaneous Fistulae
}

\author{
Hitomi Kashima, Satohiro Matsumoto (D), Shu Kojima, Yudai Koito, Takaya Miura, Takehiro Ishii, \\ Hirosato Mashima (D) \\ Department of Gastroenterology, Jichi Medical University Saitama Medical Center, Saitama, Japan \\ Correspondence: Satohiro Matsumoto, Department of Gastroenterology, Jichi Medical University Saitama Medical Center, I-847 Amanuma, Omiya, \\ Saitama, Saitama, 330-8503, Japan, Tel +8I 48647 2III, Fax +8I 48648 5I88, Email s.w.himananon@ac.auone-net.jp
}

\begin{abstract}
A 55-year-old man presented with recurrent ulcers and an enterocutaneous fistula at the anastomotic site after surgery for an ileovesical fistula and was diagnosed with intestinal Behçet's disease after undergoing surgery for enterocutaneous fistulae twice. The patient was transferred to our hospital because of recurrent enterocutaneous fistulae. He had a history of recurrent oral aphthous ulcers, folliculitis, and epididymitis and met the diagnostic/classification criteria for incomplete Behçet's disease and thus was diagnosed as having intestinal Behçet's disease. Remission induction therapy with steroids was administered for an ileal ulcer and an enterocutaneous fistula, and adalimumab was initiated for maintenance therapy. The fistula was closed, and the clinical course was favorable. Two months after initiating adalimumab, a subcutaneous abscess was detected at the site of the enterocutaneous fistula scar, and relapse of intestinal Behçet's disease was suspected. Steroids were re-administered for remission induction, followed by maintenance therapy, for which adalimumab was switched to infliximab. No relapse was detected after steroid withdrawal. No therapeutic strategies have been established for intestinal Behçet's disease. Moreover, there have been very few reports on therapeutic strategies and postoperative maintenance therapy for enterocutaneous fistulae. We thus consider this case valuable.
\end{abstract}

Keywords: intestinal Behçet's disease, adalimumab, infliximab, enterocutaneous fistulae

\section{Introduction}

Behçet's disease is a chronic systemic inflammatory disease with major symptoms of recurrent aphthous ulcers in the oral mucosa, skin manifestations, eye manifestations, and genital ulcers. ${ }^{1}$ The association of HLA-B51 with Behçet's disease is well-known. The frequency of HLA-B51 and A26 in Japanese BD patients is $60 \%$ and 30\%, respectively. ${ }^{2}$ A specific disease type centered on gastrointestinal lesions is referred to as intestinal Behçet's disease and is characterized by large punched-out-like ulcers that commonly occur in the ileocecum. The incidence of comorbid gastrointestinal lesions in patients with Behçet's disease ranges from $1 \%$ to $50 \% .^{3}$ Intestinal Behçet's disease causes perforation, hemorrhage, and severe strictures. Surgery is necessary for refractory cases and fistulas, and the rates of postoperative relapse and reoperation are high. ${ }^{4,5}$ However, medical therapies with high evidence have yet to be established, and treatment has been administered based on experience with the treatment of systemic Behçet's disease and Crohn's disease. Although many reports have indicated that anti-tumor necrosis factor (TNF)- $\alpha$ antibodies are effective, ${ }^{6,7}$ evidence regarding the efficacy of postoperative maintenance therapy is insufficient. In this case, the patient was difficult to treat because he repeatedly developed ileal ulcers accompanied by an enterocutaneous fistula at the postoperative anastomotic site after surgery for an ileovesical fistula. Although adalimumab was primary non-response as the first biologics, infliximab was effective as the 2nd biologics. Evidence-based treatment options for preventing postoperative recurrence have not been established, and more research is needed; therefore, we believe that this case is valuable. Here, we present a case of intestinal Behçet's disease treated with two types of anti-TNF- $\alpha$ antibodies. 


\section{Case Report}

The patient was a 55-year-old man. At 49 years of age, he underwent surgery for an ileovesical fistula. Subsequently, he repeatedly developed enterocutaneous fistulae at the anastomotic site, for which anastomotic site resection was performed twice. When he developed a third anastomotic enterocutaneous fistula, he was transferred to our hospital. Regarding his past history, he was treated for pulmonary tuberculosis at 27 years of age (oral administration of isoniazid $400 \mathrm{mg}+$ rifampicin $450 \mathrm{mg}$ + ethambutol $500 \mathrm{mg}$ /day for 1 year). He also had a history of recurrent oral aphthous ulcers that peaked at 35 years of age; folliculitis of the trunk, both lower legs, and genital area; and epididymitis that occurred at 50 years of age. Although he was negative for human leukocyte antigens B51 and A26, his primary symptoms were recurrent oral aphthous ulcers and folliculitis and his secondary symptoms were bilateral epididymitis and recurrent ileal ulcers. These symptoms satisfied the diagnostic/classification criteria for incomplete Behçet's disease. ${ }^{8}$ None of the following symptoms were found: uveitis, subcutaneous venous thrombosis, erythema nodosum and genital ulcers. Based on these findings, he was diagnosed with intestinal Behçet's disease that caused the formation of an ileovesical fistula and recurrent enterocutaneous fistulae at the postoperative anastomotic site. When he was transferred to our hospital, he reported passing watery diarrheal stools approximately 15 times a day and had abdominal pain. The serum C-reactive protein (CRP) level was CRP $5.1 \mathrm{mg} / \mathrm{L}$ (Normal range: $<3 \mathrm{mg} / \mathrm{L}$ ), and there was a pinhole-shaped fistula with exudate in the right lower abdomen, which was tender (Figure 1). Colonoscopy revealed ulcers at the ileocolonic anastomotic site (Figure 2A), and selective contrast imaging with gastrografin revealed a fistula through the abdominal wall (Figure 2B). Examination of biopsy tissues from the ulcer sites revealed mild inflammatory cell infiltration and negative acid-fast stain and culture for tuberculosis. Treatment included remission induction therapy with steroids under fasting and parenteral nutrition, followed by maintenance therapy with anti-TNF- $\alpha$ antibodies and enteral nutrition. Intravenous prednisolone at $40 \mathrm{mg} /$ day $(\approx 0.6 \mathrm{mg} / \mathrm{kg} /$ day) was initiated, and the fistula was closed in a week. Subsequently, the dose was tapered by 5 $\mathrm{mg} /$ week. Since the patient had a history of pulmonary tuberculosis and was positive for interferon- $\gamma$ release assay of Mycobacterium tuberculosis, isoniazid (300 mg/day) was administered to prevent the recurrence of tuberculosis, and adalimumab was initiated as maintenance therapy after 3 weeks. However, 2 months after initiating adalimumab, the patient developed abdominal pain and a subcutaneous abscess at the scar site of the enterocutaneous fistula. The serum CRP levels increased to $25.9 \mathrm{mg} / \mathrm{L}$. Thus, ileal ulcer recurrence was suspected. Although puncture and drainage were performed for the subcutaneous abscess, no communication with the intestinal tract was detected. Remission induction therapy was administered again with intravenous prednisolone at $40 \mathrm{mg} /$ day $(\approx 0.6 \mathrm{mg} / \mathrm{kg} /$ day $)$. Adalimumab was switched to infliximab at a dose of $5 \mathrm{mg} / \mathrm{kg}$. Since treatment effects were attenuated by biweekly administration of adalimumab at $40 \mathrm{mg}$, the infliximab dose was doubled to $10 \mathrm{mg} / \mathrm{kg}$ for the fourth and subsequent doses. Colonoscopy performed 2 months after initiating infliximab revealed no ulcer at the anastomotic site and showed a scarred cutaneous fistula (Figure 3A and B). Six months after initiating infliximab, no relapse was detected.

\section{Discussion}

Behçet's disease is a chronic recurrent systemic inflammatory disease characterized mainly by recurrent ulcerations in the oral mucosa and genitalia, skin manifestations, and ocular inflammations. Other clinical manifestation includes joints, vascular district, the central nervous system, and gastrointestinal tract. ${ }^{9}$ In Japan, the criteria for diagnosing Behçet's disease or intestinal Behçet's disease was created in 1987 and revised in 2003, which has been currently used. ${ }^{8,10}$ In 1990, the International Study Group for Behçet's Disease also recommended the revision of the diagnostic criteria. ${ }^{11}$ Regarding diagnostic criteria for intestinal Behçet's disease, a new classification system has been proposed by the Korean Inflammatory Bowel Disease Study Group in 2009. ${ }^{12}$ Typical ulcers in intestinal Behçet's disease are refractory and repeatedly relapse or recur and are often accompanied by intestinal complications (eg, perforation, penetration, stricture, and fistula) and require surgery. These lesions recur frequently after surgery. In many cases, they occur near the anastomotic site within 2 years of relatively early postoperative stages. ${ }^{5}$ The rate of reoperation owing to recurrence of these lesions is also high. Although the rate of recurrence within 2 years in patients not undergoing surgery is $25 \%$, the recurrence rate in patients undergoing surgery is $75 \%$, and the reoperation rate in the latter group is $37.5 \% .{ }^{13}$ 


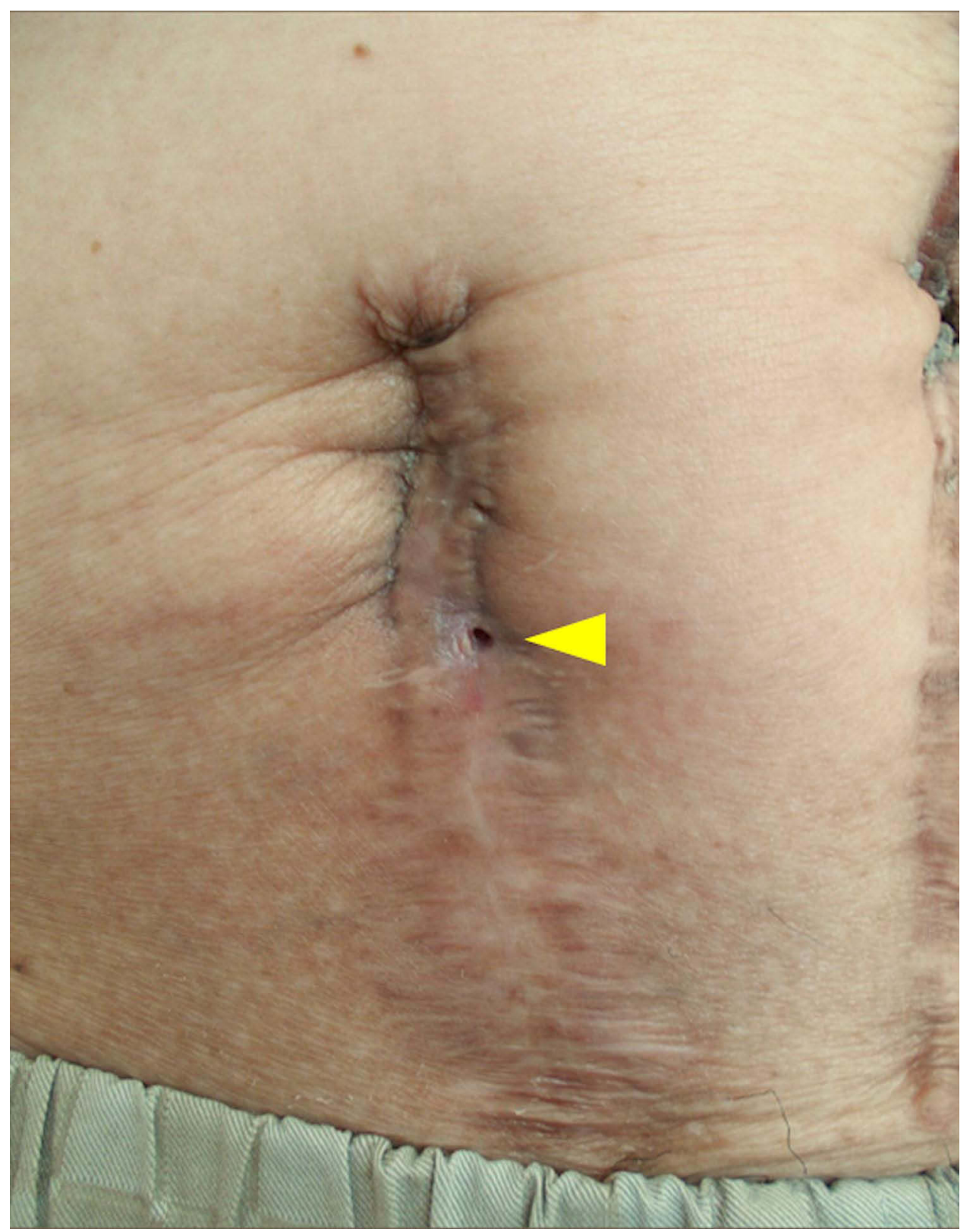

Figure I Clinical presentation of the patient at the onset of the third recurrence of anastomotic enterocutaneous fistula. A pinhole-shaped fistula with exudate in the right lower.

No medical therapies have been established with high evidence, and treatment has been administered based on experience with the treatment of systemic Behçet's disease and Crohn's disease. Many studies reported the effectiveness of anti-TNF- $\alpha$ antibodies. ${ }^{6,7}$ Despite the high postoperative recurrence rate, no therapeutic strategies to prevent recurrence have been established. While reports on the effect of maintenance therapy after surgery are limited, medical therapies are often administered according to remission maintenance therapy. Naganuma et al reported that postoperative maintenance therapy with infliximab administered every 6-8 weeks resulted in a recurrence-free state in patients with intestinal Behçet's disease for 2-3 years. ${ }^{14}$ Beyon et al reported that infliximab at $5 \mathrm{mg} / \mathrm{kg}$ is effective in improving ulcers and subsequently maintaining remission in patients with ulcers occurring at the anastomotic site within 2 weeks after ileocecal resection who fail to respond to conventional therapy with prednisolone, azathioprine, mesalamine, and colchicine. ${ }^{15}$ A prospective observational study of 462 Japanese patients with intestinal Behçet's disease treated with adalimumab reported the long-term efficacy and safety of adalimumab. ${ }^{16}$ In Japan, anti-TNF- $\alpha$ antibodies available for 


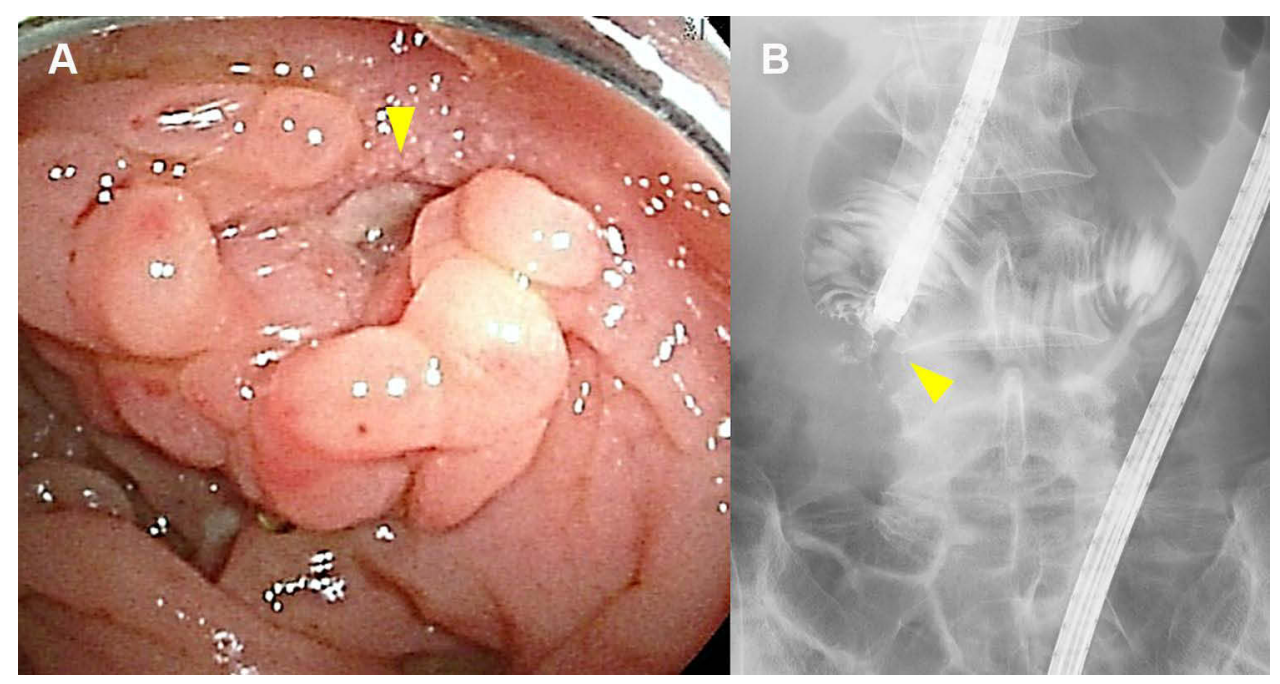

Figure 2 Colonoscopic and elective colonografy findings at the onset of the third recurrence of anastomotic enterocutaneous fistula. (A) Colonoscopy revealed ulcers at the ileocolonic anastomotic site. (B) Elective colonografy revealed a fistula through the abdominal wall.

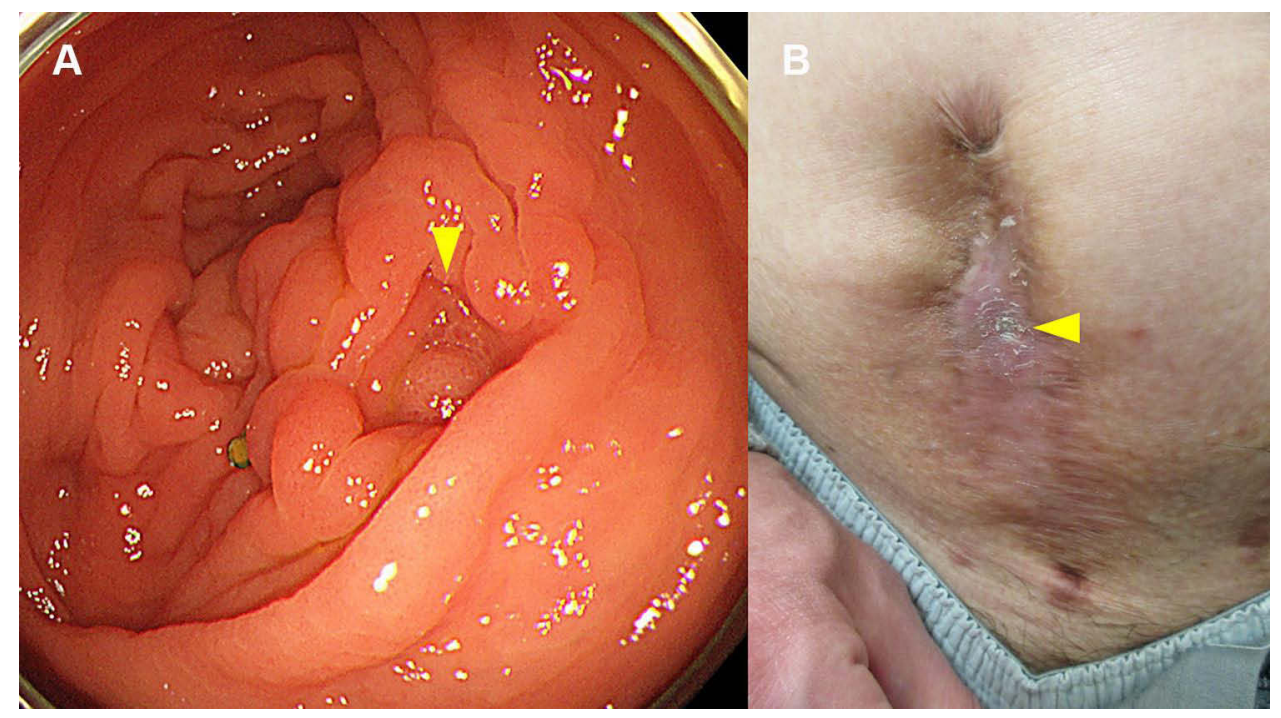

Figure 3 Colonoscopic finding and clinical presentation 2 months after initiating infliximab. (A) Colonoscopy revealed no ulcer at the anastomotic site. (B) The known fistula was completely closed.

treating intestinal Behçet's disease include infliximab and adalimumab. Administration of adalimumab at 80 mg every 2 weeks is not approved for patients with intestinal Behçet's disease who insufficiently respond to treatment, unlike in the case of patients with Crohn's disease. In contrast, administration of infliximab at a doubled dose of $10 \mathrm{mg} / \mathrm{kg}$ is approved for patients with intestinal Behçet's disease who respond insufficiently to treatment. In our case, adalimumab was initiated as the first biological agent at the patient's request. However, because primary failure occurred, adalimumab was switched to infliximab, and the dose was doubled to $10 \mathrm{mg} / \mathrm{kg}$ for the fourth and subsequent doses. The symptoms recurred 2 months after initiating adalimumab, and remission was maintained with a doubled dose of infliximab. Thus, the drug concentrations of anti-TNF- $\alpha$ antibodies appeared to be involved.

There are very few reports on enterocutaneous fistulas that complicate intestinal Behçet's disease. All patients with intestinal Behçet's disease complicated by enterocutaneous fistula had a fistula from near the anastomotic site to the skin. The time from surgery to fistula formation ranged from 7 months to 2 years. Some patients experienced spontaneous cure, whereas others required reoperation. Even after curing, the recurrence rate of enterocutaneous fistula is as high as 
$66 \% .{ }^{17}$ Since the recurrence risk of enterocutaneous fistula seems high, early therapeutic interventions are preferable. There is a report of intestinal Behçet's disease that was misdiagnosed as appendicitis and operated. ${ }^{8}$ Similarly, our patient was initially suspected to have an ileovesical fistula resulting from appendicitis and thus underwent initial surgery. The delayed diagnosis of intestinal Behçet's disease and the long time taken before therapeutic interventions may have also led to the multiple reoperations.

\section{Conclusion}

Our case findings are valuable as they demonstrated that anti-TNF- $\alpha$ antibodies were effective in preventing postoperative recurrence and treating the fistula. Although further cases need to be accumulated, the establishment of postoperative maintenance therapy is expected to improve postoperative recurrence rates. We believe that this case may cause a stir in the treatment strategy for refractory Behcet's disease.

\section{Abbreviations}

TNF, tumor necrosis factor; CRP, C-reactive protein.

\section{Institutional Approval}

No institutional approval was required for the publication of this manuscript.

\section{Ethical Considerations}

Written informed consent was obtained from the patient for publication of this Case Report and the accompanying images.

\section{Disclosure}

All authors report no conflicts of interest in this work.

\section{References}

1. Behçet H. Über rezidiverende aphtöse durch ein virüs verursachte Geschwüre am Mund, am Auge, und an den Genitalien. [On recurrent aphthous ulcers of the mouth, eyes and genitals caused by a virus]. Derm Wochenschr. 1937;36:1152-1157. German.

2. The diagnostic criteria for Behçet's disease. Ministry of health, labour and welfare web site; 2003. Available from: http://www.mhlw.go.jp/file/06Seisakujouhou-10900000-Kenkoukyoku/0000089968.pdf. Accessed September 29, 2021.

3. Hatemi I, Hatemi G, Celik AF, et al. Gastrointestinal involvement in Behçet disease. Rheum Dis Clin North Am. 2018;44(1):45-64. doi:10.1016/j. rdc.2017.09.007

4. Jung YS, Yoon JY, Lee JH, et al. Prognostic factors and long-term clinical outcomes for surgical patients with intestinal Behcet's disease. Inflamm Bowel Dis. 2011;17(7):1594-1602. doi:10.1002/ibd.21517

5. Iida M, Kobayashi H, Matsumoto T, et al. Postoperative recurrence in patients with intestinal Behçet's disease. Dis Colon Rectum. 1994;37(1):1621. doi:10.1007/BF02047208

6. Tanida S, Inoue N, Kobayashi K, et al. Adalimumab for the treatment of Japanese patients with intestinal Behçet's disease. Clin Gastroenterol Hepatol. 2015;13(5):940-948. doi:10.1016/j.cgh.2014.08.042

7. Hibi T, Hirohata S, Kijuchi H, et al. Infliximab therapy for intestinal, neurological, and vascular involvement in Behcet disease: efficacy, safety, and pharmacokinetics in a multicenter, prospective, open-label, single-arm Phase 3 study. Medicine. 2016;95(24):e3863. doi:10.1097/ MD. 0000000000003863

8. Watanabe K, Tanida S, Inoue N, et al. Evidence-based diagnosis and clinical practice guidelines for intestinal Behcet's disease 2020 edited by Intractable Diseases, the Health and Labour Sciences Research Grants. J Gastroenterol. 2020;55(7):679-700. doi:10.1007/s00535-020-01690-y

9. Kaklamani VG, Vaiopoulos G, Kaklamanis PG. Behcet's disease. Semin Arthritis Rheum. 1998;27(4):197-217. doi:10.1016/S0049-0172(98)800012

10. Mizushima Y. Recent research into Behçet's disease in Japan. Int J Tissue React. 1988;10(2):59-65.

11. International Study Group for Behçet's Disease. Criteria for diagnosis of Behçet's disease. Lancet. 1990;335(8697):1078-1080.

12. Cheon JH, Kim ES, Shin SJ, et al. Development and validation of novel diagnostic criteria for intestinal Behçet's disease in Korean patients with ileocolonic ulcers. Am J Gastroenterol. 2009;104(10):2492-2499. doi:10.1038/ajg.2009.331

13. Naganuma M, Iwao $\mathrm{Y}$, Inoue $\mathrm{N}$, et al. Analysis of clinical course and long-term prognosis of surgical and nonsurgical patients with intestinal Behçet's disease. Am J Gastroenterol. 2000;95(10):2848-2851. doi:10.1111/j.1572-0241.2000.03198.x

14. Naganuma N, Sakutaba A, Hisamatsu T. Efficacy of infliximab for induction and maintenance of remission in intestinal Behçet's disease. Inflamm Bowel Dis. 2008;14(9):1259-1264. doi:10.1002/ibd.20457

15. Beyon JS, Choi EK, Heo NY, et al. Antitumor necrosis factor-alpha therapy for early postoperative recurrence of gastrointestinal Behçet's disease: report of a case. Dis Colon Rectum. 2007;50(5):672-676. doi:10.1007/s10350-006-0813-x 
16. Suzuki Y, Hagiwara T, Kobayashi M, Morita K, Shimamoto T, Hibi T. Long-term safety and effectiveness of Adalimumab in 462 patients with intestinal Behcet's disease: results from a large real-world observational study. Intest Res. 2021;19(3):301-312. doi:10.5217/ir.2020.00013

17. Chung HJ, Goo BC, Lee JH, et al. Behçet's disease combined with various types of fistula. Yonsei Med J. 2005;46(5):625-628. doi:10.3349/ ymj.2005.46.5.625

\section{Publish your work in this journal}

Biologics: Targets and Therapy is an international, peer-reviewed journal focusing on the patho-physiological rationale for and clinical application of Biologic agents in the management of autoimmune diseases, cancers or other pathologies where a molecular target can be identified. This journal is indexed on PubMed Central, CAS, EMBase, Scopus and the Elsevier Bibliographic databases. The manuscript management system is completely online and includes a very quick and fair peer-review system, which is all easy to use. Visit http://www.dovepress.com/ testimonials.php to read real quotes from published authors.

Submit your manuscript here: https://www.dovepress.com/biologics-targets-and-therapy-journal 